\title{
Use of Castor Oil-based Polyurethane Adhesive in the Production of Glued Laminated Timber Beams
}

\author{
Maximiliano dos Anjos Azambuja ${ }^{\text {a*, Antonio Alves Dias }}{ }^{\mathrm{b}}$ \\ anterunit Area of Materials Sciences and Engineering, University of São Paulo - USP, Brazil \\ ${ }^{\mathrm{b}}$ São Carlos School of Engeneering, University of São Paulo - USP, Brazil
}

Received: December 13, 2005; Revised: June 8, 2006

\begin{abstract}
Researchers from the Polymer Technology and Analytical Chemistry (LQATP) group at the São Carlos Institute of Chemistry, University of São Paulo, developed a polyurethane adhesive based on castor oil. In addition to deriving it from a renewable source, this adhesive is nonaggressive to humans and the environment. The purpose of this study is to investigate the feasible use of polyurethane adhesive based on castor oil in the production of 12 beams of Glulam, using the species Pinus caribea hondurensis and Eucaliptus grandis. The structural performance of the beams of Glulam was evaluated through static bending tests. The results obtained enabled to conclude good efficiency of the polyurethane adhesive based on castor oil, for use in Glulam.
\end{abstract}

Keywords: wood, castor oil adhesive, glulam

\section{Introduction}

Glued laminated timber (GLULAM) is an indispensable technique that allows for the use of reforested wood for structural purposes, since these wood species usually contain defects such as knots and cracks, which results in their application in the form of solid wood to be unfeasible. However, GLULAM is not yet operationally viable in Brazil, specifically on account of its high production cost.

A castor oil-based polyurethane (Ricinus communis) is an alternative for the production of GLULAM, currently being developed by researchers from the Polymer Technology and Analytical Chemistry (LQATP) group, in the São Carlos Institute of Chemistry, University of São Paulo. Besides representing, in terms of cost, a potentially more feasible alternative for the production of GLULAM, this adhesive has the advantage of being non-aggressive to humans and the environment, in addition to the fact that it is derived from a natural and renewable source ${ }^{1,2}$.

Several investigations have assessed the strength of castor oil adhesive in GLULAM, using test specimens standardized by the ABNT-NBR $7190 / 97^{3}$ for the design of wooden structures, with satisfactory results. However, until the present moment, no study has been performed to evaluate the behavior of this adhesive in structural elements.

The purpose of this study, therefore, is to investigate the behavior of this polyurethane adhesive in straight GLULAM beams, evaluating its efficiency in the lamination of beams and its behavior in the rupture of structural elements. This study also aims to assess specific gluing and manufacturing techniques for the new adhesive, whose characteristics differ from traditional ones.

\section{Wood}

Owing to the fact that wood is one of the most complex materials used in engineering, an in-depth understanding of its properties is indispensable in order to consent its use competitively.

Wood is considered an anisotropic and hygroscopic material, losing and gaining moisture as a result of climatic variations. Such losses and gains cause different strains in the radial and tangential directions of the trunk's transversal section and in the longitudinal direction. Anisotropy in wood produces different properties of mechanical strength in the transversal direction and along the fibers, with the greatest strength located in the axial direction, Panshin ${ }^{4}$.

Table 1 indicates the elastic and mechanical strength characteristics listed under the ABNT-NBR $7190 / 97^{3}$ for Eucalyptus grandis (leafy) and Pinus caribea var. hondurensis (conifer), the two species studied here.

\section{Adhesive}

The researchers of the Polymer Technology and Analytical Chemistry (LQATP) group of the University of São Paulo in São Carlos have developed a polyurethane resin based on the castor oil plant. This adhesive possesses several advantages, such as handling at ambient temperature, strong resistance to water and ultraviolet rays, high mechanical strength, and the fact that it derives from a renewable source ${ }^{5}$.

Basically, the adhesive is obtained by cold polymerization of the polyol and prepolymer (castor oil-based) mixture, a reaction leading to the formation of the polyurethane.

This castor oil-based adhesive has several applications, one of the them being glued laminated timber. In his study on GLULAM, Jesus $^{6}$ confirmed the viability of applying this adhesive in glued laminated timber. He also determined the most appropriate gluing parameters to optimize the final strength of GLULAM by carrying out tests on specimens based on the ABNT-NBR 7190/97³ standard for wood structure design.

\section{Glued Laminated Wood Structures}

One form to rationalize the use of wood for structural purposes is using glued laminated Timber, which is produced by gluing together short narrow pieces of wood so that their fibers run parallel to the 
Table 1. Properties of wood species (Source: NBR 7109:1997)

\begin{tabular}{lcc}
\hline & $\begin{array}{c}\text { E. Grandis } \\
\text { Eucalyptus } \\
\text { grandis }\end{array}$ & $\begin{array}{c}\text { Pinus hondurensis } \\
\text { Pinus caribea } \\
\text { var.hondurensis }\end{array}$ \\
\hline $\begin{array}{l}\text { Specific apparent mass } \\
(\mathrm{u}=12 \%)\left(\mathrm{kg} / \mathrm{m}^{3}\right)\end{array}$ & 640 & 535 \\
$\begin{array}{l}\text { Parallel compressive strength } \\
(\mathrm{MPa})\end{array}$ & 40.3 & 42.3 \\
$\begin{array}{l}\text { Tensile strength along the } \\
\text { fibers (MPa) }\end{array}$ & 70.2 & 50.3 \\
$\begin{array}{l}\text { Tensile strength normal to } \\
\text { the fibers (MPa) }\end{array}$ & 2.6 & 2.6 \\
$\begin{array}{l}\text { Shear strength (MPa) } \\
\text { Longitudinal modulus of } \\
\text { elasticity (MPa) }\end{array}$ & 7.0 & 7.8 \\
\hline
\end{tabular}

length of the piece to be manufactured, according to the description given by Jesus ${ }^{6}$.

This technique not only precludes material losses but also produces large-dimensioned and multiple-shaped pieces, enabling to have control of the material's characteristics in the different positions of the structural element, and considerably reducing the occurrence of defects (knots, cracks, etc.), which are typical of large pieces of solid sawn wood.

Glulam beams offer many advantages as structural elements in comparison to solid wood members involving an industrial production process and there is strict quality control. On the other hand, this process requires specialized labor, equipment and special techniques. Moreover, particularly in Brazil, the adhesive used in this process is very expensive, increasing the product's market price.

\section{Materials and Methods}

\subsection{Adhesive application technique}

The primary goal of this study was to determine the manufacturing procedures of glued laminated timber beams. The development of a new type of castor oil adhesive, less viscous and longer lasting than the adhesive originally studied, was the first step in making its application feasible in large dimension wood elements, in which the service life and workability of the original adhesive were unsuitable for gluing.

Note: service life is defined as the time elapsed between the adhesive preparation and the beginning of its hardening.

Thus, in this study, equal parts in weight of polyol 25040 and prepolymer A249 were used to produce the adhesive. Another very important factor in castor oil adhesive is that mixing the components without allowing them to be in contact with air increases the quality of the adhesive ${ }^{7-9}$. The recommended procedures are given in sequence in Figure 1.

The procedure follows the steps listed below:

a) Preparation of the plastic packaging containing the two components of the adhesive in the proper amounts, kept separately; b) Mixture of the components inside the plastic bag just prior to the application of the adhesive; c) Cut out one of the corners of the plastic bag containing the mixed adhesive to form a kind of applicator funnel; d) Apply the adhesive on the surface (both surfaces) with the help of the "applicator"; e) Spread the adhesive over the surfaces to be glued, using a wooden spatula; and f) Assemble the two surfaces together, leaving the piece ready for the application of gluing pressure.
The procedure for the beams is the same as that illustrated in Figure 1, with one bag of adhesive prepared for each layer to be glued. Since it takes an average of 2.5 minutes to spread the adhesive over the surface (depending, of course, on the extent of the surface), the time it takes to prepare the mixture will be the same, that is 2.5 minutes.

The gluing pressure was applied by steel plates fixed with bolts and nuts, while the gluing pressure was controlled by a torque meter pre-calibrated to apply the necessary load on the bolts, therefore subjecting the entire beam to a given amount of pressure.

In this study, pressure was applied on the beams glued with resorcinol formaldehyde adhesive for 12 hours (following the manufacturer's technical recommendations) and on the beams glued with castor oil adhesive pressure was applied for 24 hours. This 24-hour period was based on the results obtained from preliminary tests on the adhesive, not discussed herein. The pressure used in both cases was $0.6 \mathrm{MPa}^{10-12}$.

Figure 2 shows a diagram of the application of gluing pressure.

Before gluing, all the layers used in the manufacture of the beams were characterized in terms of their modulus of elasticity through bending tests aimed at determining their rigidity in order to evaluate their laminating efficiency and the rational positioning of the layers on the beams so as to produce beams with similar rigidities.

\subsection{Structural evaluation tests}

The use of castor oil-based adhesives in beams was evaluated by testing 12 beams, six of which were made of the species Eucalyptus grandis and the other six of Pinus caribea hondurensis. For each specie, three beams with dimensions of $5 \times 15 \times 230 \mathrm{~cm}$ were assembled and the other three with $5 \times 10.5 \times 230 \mathrm{~cm}$. Conventional resorcinol formaldehyde adhesive ${ }^{13}$ was used to glue each one of the species and dimensions in order to compare the results.

The tests for the experimental evaluation of the structural behavior of straight beams prepared for this study were based on the recommendations of the ABNT-NBR $7190 / 97^{3}$ and of the ASTM-D $198 / 84^{14}$. The purpose of these tests was to determine the flexural stiffness and strength of the beams. Figure 3 illustrates the bending test.

The bending tests were carried out by applying loads on the four points bending test of the beams, which were simply supported, with span of $220 \mathrm{~cm}$. Lateral locking points were defined, following the recommendations of the ASTM-D198/84 ${ }^{14}$, in order to avoid lateral instability, which may occur during bending tests. The load was applied according to the loading cycle recommended to the bending test by ABNT-NBR 7190/973. This last standard was applied only for this purpose.

\subsection{Theoretical analysis and results}

The beams' theoretical rigidity modulus (EI) was determined based on the values of the elasticity modulus, the dimensions of the transversal sections and the position of the layers on the beams, which were defined in the layer characterization phase.

Each of the layers had a Height value, $h_{\text {, }}$, and a Modulus of Elasticity, $E_{i}$, which were obtained in the material's characterization phase. All the veneers (layers) had the same width, inasmuch as the beams were slimmed down to the same width $b$ value after gluing.

As the Rigidity Modulus of each layer is calculated as the product of its Modulus of Elasticity $E_{i}$ and its Moment of Inertia $I_{i}$, for calculation purposes, $\mathrm{E}_{\mathrm{i}}$ is considered as a generic value $\mathrm{E}_{c}$ (e.g., the mean value of the layers that comprise the beam) and the Moment of Inertia value can be considered as a value $I_{c i}$, which result in the same Rigidity Modulus value.

$$
\mathrm{I}_{c i} \cdot \mathrm{E}_{c}=\mathrm{E}_{i} \mathrm{I}_{i} \quad \frac{\mathrm{b}_{c i} \mathrm{~h}_{i}^{3}}{12} \mathrm{E}_{c i}=\frac{\mathrm{b}_{i} \mathrm{~h}_{i}^{3}}{12} \mathrm{E}_{i}
$$




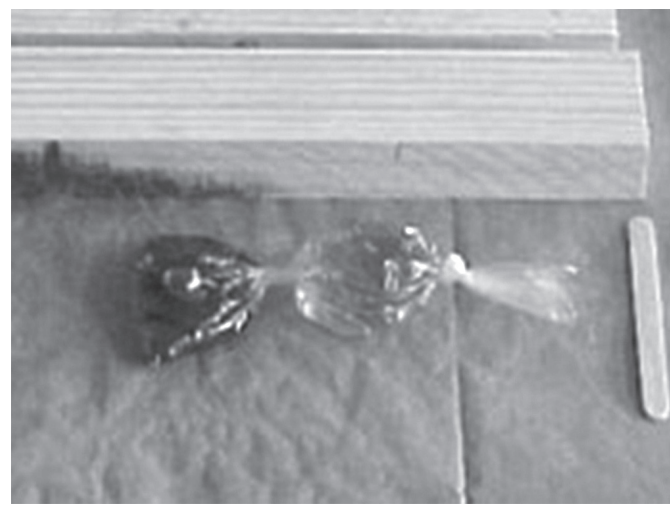

(a)

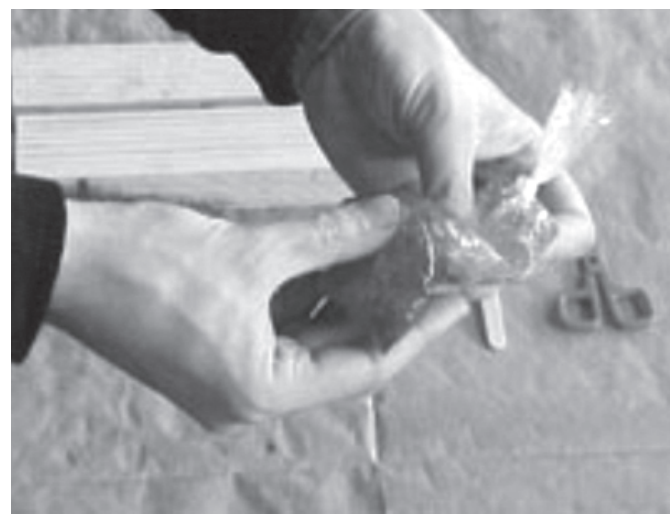

(b)

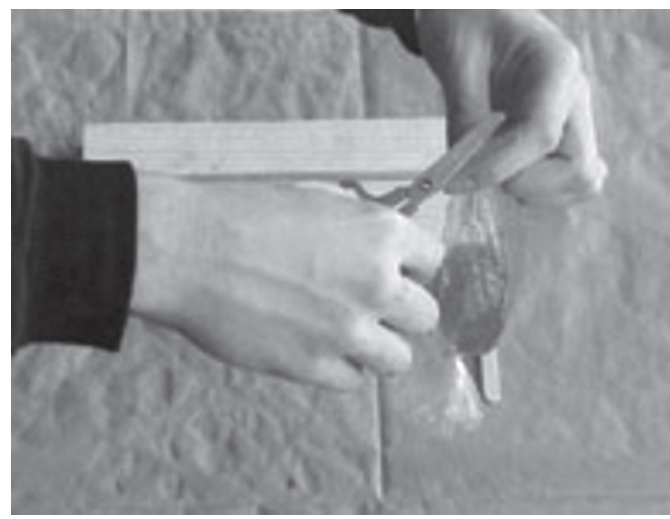

(c)

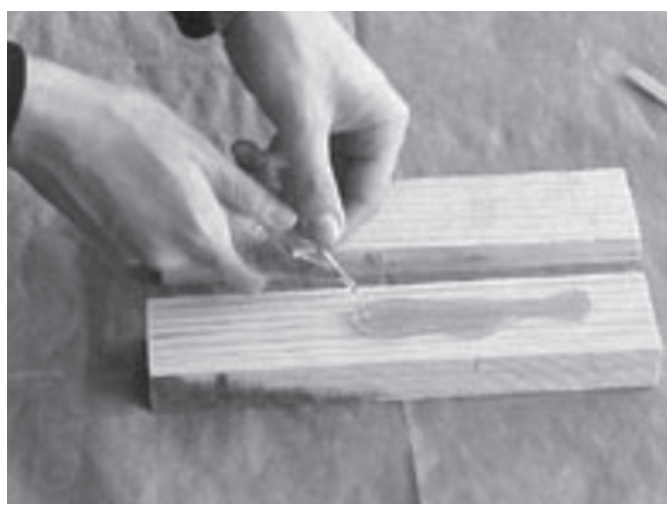

(d)

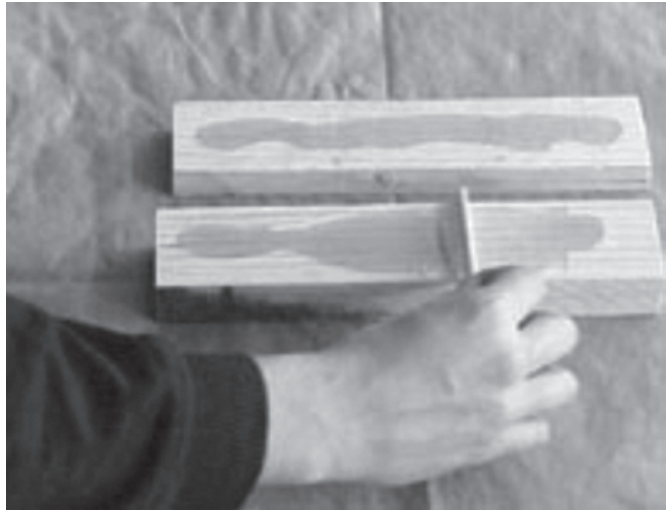

(e)

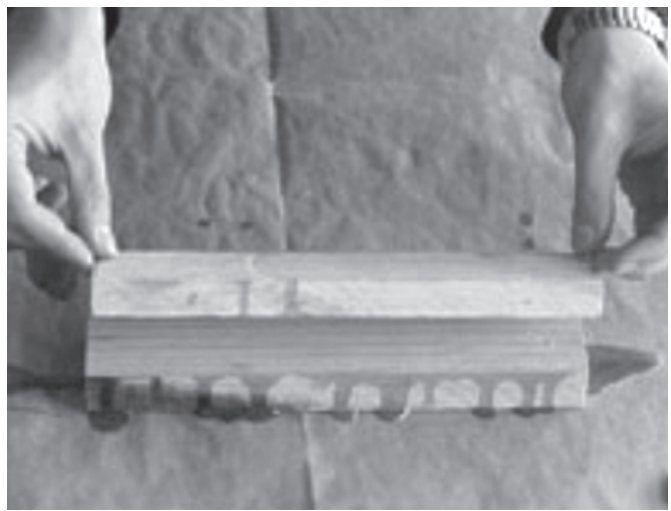

(f)

Figure 1. Preparation and application procedures for castor oil-based polyurethane adhesive.

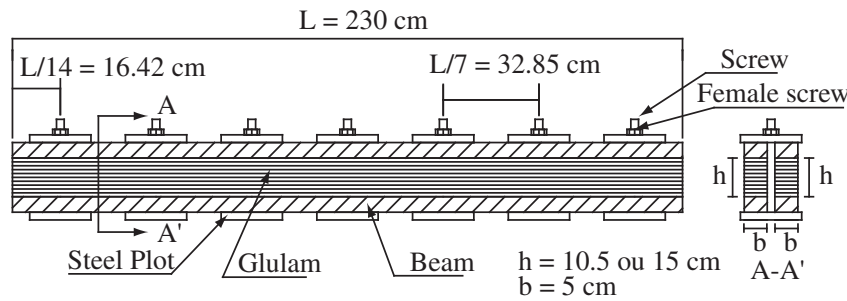

Figure 2. Application of gluing pressure on beams. Source: Maximiliano dos Anjos Azambuja.

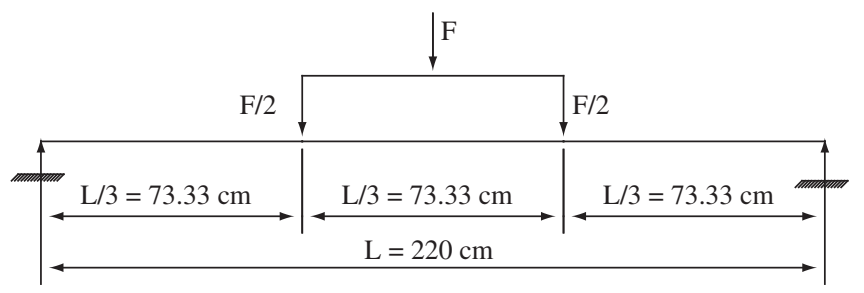

Figure 3. Diagram of bending test. Source: Maximiliano dos Anjos Azambuja. 
Thus, the veneer can be considered as having uniform Modulus of Elasticity with a value $\mathrm{E}_{\mathrm{c}}$, substituting the real width $\left(\mathrm{b}_{\mathrm{i}}\right)$ of each layer, by a ficticious value (bci) ${ }^{15}$ :

$$
\mathrm{b}_{c i}=\frac{\mathrm{E}_{i}}{\mathrm{E}_{c i}} \mathbf{b}_{i}
$$

To consider the beam's theoretical EI value, one calculates the product of the generic value of $\mathrm{E}$ with the sum of the Moment of Inertia of each of the layers (including the transport to the center of gravity of the set of layers), using the $b_{c i}$ value, as shown by Equação 3 .

$$
\mathrm{EI}_{\text {theoretic }}=\mathrm{E}_{c} \cdot \sum_{\mathrm{i}=1}^{\mathrm{n}}\left(\frac{\mathrm{b}_{c i} \cdot \mathrm{h}_{i}^{3}}{12}+\mathrm{b}_{c i} \mathrm{~h}_{\mathrm{i}} \mathrm{y}_{\mathrm{i}}^{2}\right)
$$

where $y$ is the distance from the center of gravity of the layer to the center of gravity of the beam (set of layers).

The experimental EI product was calculated based on the values of vertical displacement observed in the bending tests carried out on the beams. This analysis considered the influence of the shear stress on the vertical displacement values. The Theory of Strain Energy was used to assess the influence of shear stress on the beams' vertical displacements.

Developing this expression for the load on the straight beams of this study, and taking into account the fact that normal and torsion stresses do not occur with this load on the structure, one comes up with the following expressions:

- For displacements in mid-span:

$$
\mathrm{EI}_{\text {effective }}=\frac{5 \mathrm{~kL}^{3}}{324\left(1-\frac{\mathrm{kL}}{5 \mathrm{GA}}\right)}
$$

- For displacements at the points where loads were applied:

$$
\mathrm{EI}_{\text {effective }}=\frac{23 \mathrm{~kL}^{3}}{1296\left(1-\frac{\mathrm{kL}}{5 \mathrm{GA}}\right)}
$$

where $\mathrm{A}$ is the area of the beam's transversal section.

The beam was considered to be working in a linear elastic phase, with the relation $\mathrm{P}=\mathrm{k} . \mathrm{v}$, in other words, $\mathrm{k}=\mathrm{P} / \mathrm{v}$. Hence, $\mathrm{k}$ is the value of the angular coefficient of the straight line obtained by Linear Regression of the Load versus Displacement ratio obtained experimentally.

The value of the EI $I_{\text {effective }}$ product of the beams was adopted as the $\mathrm{EI}_{\text {effective }}$ value obtained by the vertical displacements in mid-span, while the values at the other two points (middle thirds) were calculated simply for experimental results control.

The lamination efficiency can be understood as the relation between the experimental and the theoretical rigidities, both calculated by the process explained earlier.

Thus, one finds that the efficiency $\eta(\%)$ is given by:

$$
\eta(\%)=100 \cdot \frac{E_{\text {effective }}}{{E I_{\text {theoretic }}}}
$$

Tables 2 and 3 list the efficiency values obtained for the beams of this study.

Table 4 lists the values for the moment of rupture observed in the beams.

\section{Discussion}

The structural behavior evaluated by means of bending tests showed similar results in the beams glued with the adhesive under study, displaying the same efficiency for the two adhesives, although it can be stated that the castor oil-based adhesive demostrated better performance.

The lamination efficiency was evaluated through the ratio between the effective EI product and the theoretical EI. In the case of the Eucalyptus grandis beams, the efficiency observed was lower than for Pinus caribea var. hondurensis species, confirming the expectation that adhesives display greater adherence to lower density species.

Efficiency values slightly above $100 \%$ were found in the Pinus caribea var. hondurensis species for beams glued with the castor oil adhesive, which was not the case for the resorcinol formaldehyde adhesive. This fact may be attributed to the findings of Jesus ${ }^{6}$, who found ratios between glued and solid test specimens of more than $100 \%$. According to the author, this may be considered as evidence of the wood's higher strength in the regions where the adhesive penetrates, thus increasing its final strength. This hypothesis is more valid in the

\begin{tabular}{|c|c|c|c|c|c|c|}
\hline & Beam 1 & Beam 2 & Beam 3 & Beam 4 & Beam 5 & Beam 6 \\
\hline Adhesive & Cascophen & Castor oil & Castor oil & Cascophen & Castor oil & Castor oil \\
\hline Effective EI $\left(10^{3}\right.$ kN.cm $\left.{ }^{2}\right)$ & 2532 & 3145 & 2449 & 805 & 879 & 929 \\
\hline Theoretical EI $\left(10^{3} \mathrm{kN} . \mathrm{cm}^{2}\right)$ & 2754 & 3206 & 2757 & 957 & 928 & 994 \\
\hline Efficiency (\%) & 91.9 & 98.1 & 88.8 & 84.1 & 94.8 & 93.4 \\
\hline
\end{tabular}
case of less dense species, such as Pinus caribea var. hondurensis.

Table 4. Moment of rupture of the beams (kN.m).

\begin{tabular}{|c|c|c|c|c|c|c|}
\hline & Beam 1 & Beam 2 & Beam 3 & Beam 4 & Beam 5 & Beam 6 \\
\hline Adhesive & Cascophen & Castor oil & Castor oil & Cascophen & Castor oil & Castor oil \\
\hline Effective EI $\left(10^{3}\right.$ kN.cm $\left.{ }^{2}\right)$ & 1219 & 1250 & 1259 & 367 & 432 & 426 \\
\hline Theoretical EI $\left(10^{3}\right.$ kN.cm $\left.{ }^{2}\right)$ & 1229 & 1195 & 1208 & 379 & 407 & 401 \\
\hline Efficiency (\%) & 99.1 & 104.6 & 104.2 & 97.0 & 106.0 & 106.3 \\
\hline
\end{tabular}

\begin{tabular}{clcc}
\hline Beam & Adhesive & $\begin{array}{c}\text { Pinus caribea var. } \\
\text { hondurensis }\end{array}$ & Eucalyptus grandis \\
\hline B-1 & Cascophen & 10.12 & 17.31 \\
B-2 & Castor oil & 9.13 & 20.42 \\
B-3 & Castor oil & 7.59 & 18.66 \\
B-4 & Cascophen & 3.78 & 7.59 \\
B-5 & Castor oil & 4.66 & 7.41 \\
B-6 & Castor oil & 4.66 & 8.76 \\
\hline
\end{tabular}

Table 2. Summary of the efficiency values of the Eucalyptus grandis beams.

Table 3. Summary of the efficiency values of the Pinus caribea var. hondurensis beams. 
As to the rupture mode observed in the beams, failure of the structural element occurred basically as a result of normal flexural stresses. Rupture by shearing stress was observed to be the consequence of rupture resulting from the effect of normal stresses, which is those commonly observed in wood. This result evidenced the adequate behavior of the adhesive.

A few minor portions of some of the beams showed rupture by shearing of the glue, which is believed to occur only after rupture of the beam due to the effect of normal stresses. No major areas of fragility (rupture) were found along the glue line for either of the two adhesives.

\section{Conclusions}

The new kind of castor oil adhesive used in this study presented adequate characteristics of strength, which were evaluated in preliminary tests and which indicated the need for longer gluing pressure times in comparison to that of the original adhesive. The new variety of adhesive proved to be far more appropriate for gluing than the original adhesive, owing to its longer service life and lower viscosity.

The procedures for the gluing process used in this study proved more difficult for the application of the castor oil-based adhesive when compared to the resorcinol formaldehyde glue.

The structural efficiency in the lamination obtained through the two adhesives was quite similar, with greater efficiency shown by the Pinus caribea var. hondurensis species than the Eucalyptus grandis species, on account of its lower density (greater porosity). The Pinus caribea var. hondurensis beams showed a lamination efficiency of over $100 \%$, which suggests an increase in the wood's strength due to the penetration of the castor oil adhesive.

The rupture load values observed in the beams' bending tests were close to those of the similar beams glued with the different kinds of adhesive. Rupture of the Pinus caribea var. hondurensis beams occurred more suddenly than that observed in the Eucalyptus grandis beams. The rupture mode in both species revealed that failure was caused by the high normal flexural stresses. No failure by shearing stress was found along the layer of glue.

As a final conclusion, it can be stated that the use of castor oilbased polyurethane adhesive is viable in the manufacture of glued laminated timber, from the standpoint of structural performance.

\section{Acknowledgments}

The financial support of the CAPES, is gratefully acknowledged.

\section{References}

1. Araújo LCR. Caracterização química e mecânica de poliuretanas elastoméricas baseadas em materiais oleoquímicos. Master's Dissertation. São Carlos: University of São Paulo; 1992.

2. Neto SC. Caracterização físico-químicas de um poliuretano derivado do óleo de mamona utilizado para implantes ósseos. Doctoral Thesis. São Carlos: University of São Paulo; 1997.

3. Associação Brasileira de Normas Técnicas. NBR 7190, Projeto de Estruturas de Madeira. Rio de Janeiro; 1997.

4. Panshin AJ, De Zeeuw C. Textbook of wood technology. New York, Mc Grow-Hill Company; 1980.

5. Plepis AMG. Caracterização térmica e Viscoelástica de Resinas Poliuretanas Derivadas de Óleo de Mamona. [Doctoral Thesis]. São Carlos: University of São Paulo; 1991.

6. Jesus JMH. Estudo do adesivo poliuretano à base de mamona em madeira laminada colada (MLC). Doctoral thesis. São Carlos: University of São Paulo; 2000.

7. Tessoni BC. Madeira laminada colada na arquitetura: sistematização de obras executadas no Brasil. Master's Dissertation. São Carlos: University of São Paulo; 1996.

8. Carrasco EVM. Resistência, elasticidade e distribuição de tensões nas vigas retas de madeira laminada colada. [USP Doctoral Thesis]. São Carlos: University of São Paulo; 1989.

9. Helmeister JC, Ferreira CEM, Carrasco EVM. In: Encontro Brasileiro em Madeiras e Estruturas de Madeira. Tecnologia de adesivos poliuretanos: propriedades e aplicações em madeira; 1989; EBRAMEM, São Carlos, SP. São Carlos: University of São Paulo; 1989. n. 6, p. 39-75.

10. Skeist I. Handbook of adhesives. New York: Van Nostrand Reinhold, 3 ed; 1990; n. 3, p. 598-610.

11. Houwink R, Salomon G. Adhesion and adhesives. Amsterdam. Elsevier; 1965.

12. Vick CB. Wood Handbook, Wood as an Engineering Material, Washington, Forest Products Laboratory, chapter 9, USDA/FS, 1999.

13. Cascophen RS-216-M, Technical Bulletin: Phenol resorcinol formaldehyde based adhesive, Chemical Alba Industry. 2005 [cited 2005 october 24]; Available from http://www.albaadesivos.com.br/max/75/june/24/ html.

14. ASTM D198-84. Methods of Static Tests of Timbers in Structural Sizes. Philadelphia, PA, 1984.

15. Schiel F. Introdução à Resistência dos Materiais, Ed. Harba; 1984. p. 395 , São Paulo. 